Document downloaded from:

http://hdl.handle.net/10251/98642

This paper must be cited as:

Verde Trindade, M.; Harby Mohamed Abd Alaal, K.; De Boer, R.; Corberán, JM. (2016). Performance evaluation of a waste-heat driven adsorption system for automotive airconditioning: Part II - Performance optimization under different real driving conditions. Energy. 115:996-1009. doi:10.1016/j.energy.2016.09.086

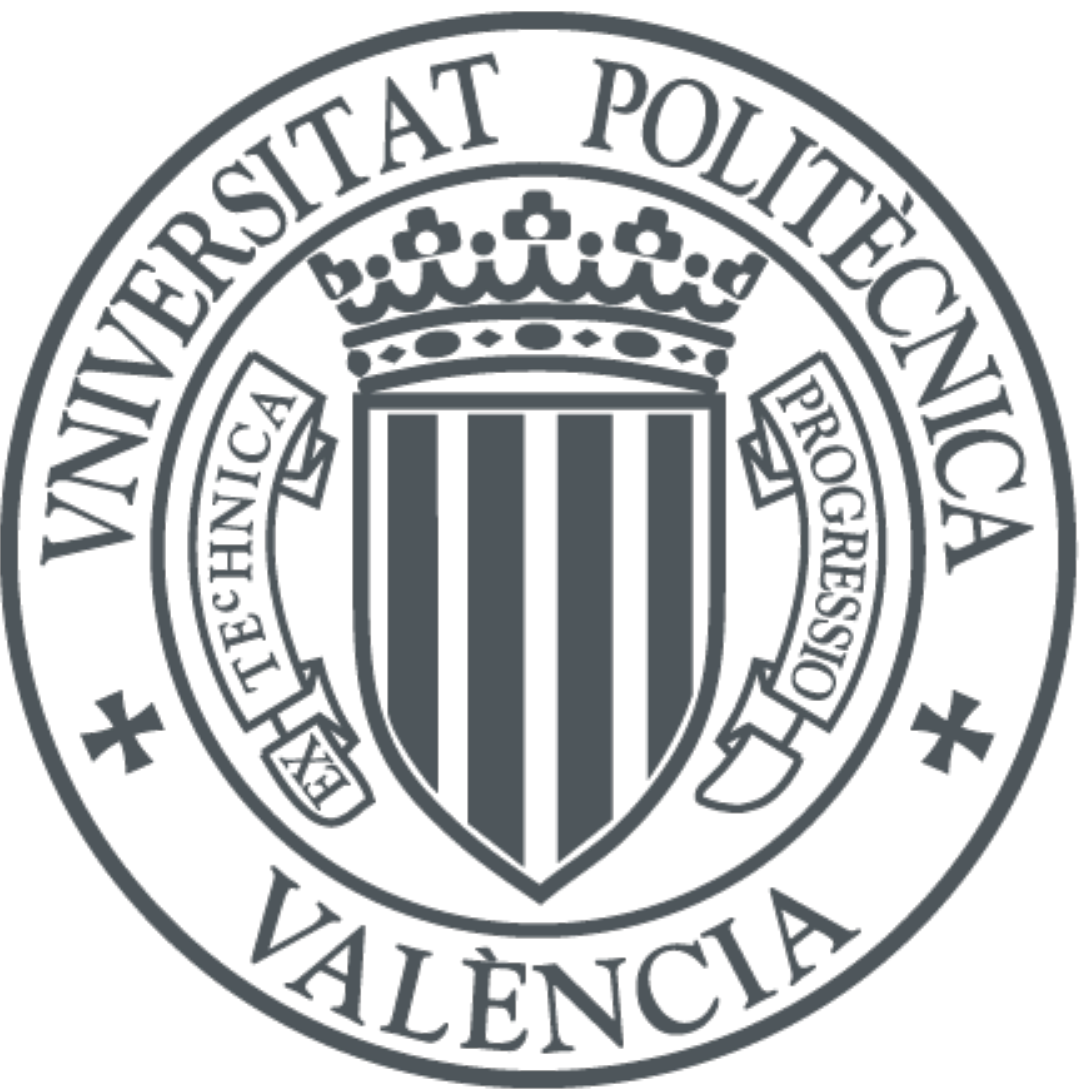

The final publication is available at

http://doi.org/10.1016/j.energy.2016.09.086

Copyright Elsevier

Additional Information 


\title{
Performance evaluation of a waste heat driven adsorption system for automotive air-conditioning: Part II - Performance optimization under different real driving conditions
}

\author{
M. Verde ${ }^{\mathrm{a}}$, K. Harby ${ }^{\mathrm{a}, \mathrm{b}}$, Robert de Boerc, José M. Corberán ${ }^{\mathrm{a}}$ \\ anstituto de Ingeniería Energética, Universidad Politécnica de Valencia, Camino de Vera 14, ES 46022 \\ Valencia, Spain \\ bMechanical Power Engineering and Energy Department, Faculty of Engineering, Minia University, 61519, \\ Minia, Egypt \\ 'Energy research Centre of the Netherlands, ECN, PO Box 1, 1755 ZG, Petten, The Netherlands

\section{${ }^{*}$ Corresponding author:} \\ Email:
}

\begin{abstract}
In this part, Part II of a two-part study, the validated transient model in part I is incorporated into the global model of a vehicle in order to predict the dynamic performance of the system under real driving conditions. The overall model takes into account all systems and subsystem components to simulate the performance of the entire system and predict the cabin temperature at the available waste-heat. The system was implemented in a Fiat Grande Punto vehicle and the experimental tests were performed at the Centro Ricerche Fiat (CRF), Italy laboratories. The overall weight of the on-board system is about $86 \mathrm{~kg}$. Different design configurations are investigated to explore further improvements of the performance. Results showed that, the model can predict well the transient performance of the entire system under different start-up and ambient conditions. Using two radiators instead of one radiator increases the cooling capacity by $7.0 \%$ and decreases the cabin temperature by $9.1 \%$. At the warming up period, the adsorption system faces serious difficulties to start to produce the required cooling. These difficulties mainly depend on the initial state of the uptake at the reactors. Possible strategies to avoid this problem are studied and compared. In general, it is proved that the amount of engine waste-heat available is sufficient to produce enough cooling to keep reasonably comfortable temperatures in the cabin.
\end{abstract}


Keywords: Optimization, Automobile cabin, Silica-gel, Adsorption system, Waste heat recovery.

\section{Introduction}

Traditional vapor compression refrigeration systems (VCRS) require high energy consumption and contribute significantly to greenhouse gas emissions [1]. Thermally driven adsorption systems are under development nowadays. These systems can minimize the environmental impact and save primary energy when sued as alternative to traditional VCRS, especially in automotive applications [2].

Several adsorption systems and prototypes have been built and tested in the recent years for automobile air conditioning (A/C). For example, Vasta et al. [3] developed and tested an adsorption A/C system for a truck cabin, the system powered by the thermal energy coming from the engine coolant loop. Results showed that the system is able to deliver an average cooling power of $2 \mathrm{~kW}$ and keep the truck cabin temperature around $24^{\circ} \mathrm{C}$. Verde et al. [4] constructed and tested an innovative adsorption A/C system for a truck cabin by using zeolite-water pair. The overall weight and volume of the prototype were about $60 \mathrm{~kg}$ and $170 \mathrm{dm}^{3}$ respectively. A dynamic model was proposed to simulate the engine operation through a standard driving cycle to evaluate the waste heat available at the engine hydraulic loop, the cooling capacity and the temperature and humidity of the air inside the truck cabin. The proposed system can produce an average cooling power of about 2-3 kW. Tamainot-Telto et al. [5] designed a novel adsorption prototype with activated carbonammonia pair. The system powered by waste-heat (at $90{ }^{\circ} \mathrm{C}$ ) from engine coolant water. An average cooling power about of $1.6 \mathrm{~kW}$ with an average COP of 0.22 are obtained. Wang et al. [6] presented a novel zeolite-water adsorption A/C system for locomotive operator cabin. The system can deliver cooling effect of $5 \mathrm{~kW}$ and COP of 0.25 . The chilled water produced was about $8-12^{\circ} \mathrm{C}$ for the fan coil in the locomotive cabin. Jiangzhou et al. [7] developed an adsorption prototype for a locomotive driver-cabin air conditioning employing zeolite-water pair. The weight of the prototype was about $300 \mathrm{~kg}$. The system can produce cooling power of about $4.5 \mathrm{~kW}$ with COP of 0.25. Zhang [8] designed and tested an automobile adsorption chiller using zeolite-water pair driven by waste-heat of a diesel engine. A specific cooling power of $25.7 \mathrm{~W} / \mathrm{kg}$ at COP of 0.38 were obtained. 
Most of the research on adsorption cooling systems is related to the development of mathematical models in order to predict the system behaviour and improve its performance by optimizing the operating and design parameters. However, the modern developments are focusing on dynamic models which give a more clear idea about the dynamic behaviour of the transient heat and mass transfer processes present in the beds [9-12]. Several studies have been focused on optimizing the performance of the adsorption cooling system [10, 11, 13-16].

The outcome from the previous literature showing encouraging results when using adsorption cooling systems in automotive $\mathrm{A} / \mathrm{C}$ applications. These systems are in general optimized to lead to maximum cooling power regardless the COP since the employed activating energy is waste heat. However, further studies and improvement on these systems are needed in order to enhance and optimize their performance, especially at the strongly dynamic conditions characteristic of automotive application with a huge variability of the ambient conditions, and of the availability of the waste heat. In this second part, Part II of a two-part study, performance and optimization of a silica gel-water onboard adsorption system are investigated based on the validated dynamic model proposed in the first part of this paper, Part I [17]. In the first part, an improved lumped parameter model has been developed and validated against the experimental data of an adsorption chiller prototype tested at the lab under the frame of TOPMACS project [18]. In this part, the system performance, as well as the cabin temperature, is analyzed under real driving conditions and different start-up strategies, for different ambient conditions. In addition, some parametric studies have been carried out to evaluate the differences in performance due to different design (layout) configuration under various operation strategies in order to explore further improvements of the system performance.

The overall model was used to simulate the performance of the entire system (engine, adsorption system, heating and cooling circuits, chilled water circuit and cabin) under real driving conditions of a car. Therefore, the system can be virtually assessed, similarly to the real system during typical standard characterization tests. Development of an overall model 
for the proposed system was a particular challenging task since the system is complex and comprises of a great number of different components. Under real driving conditions the available waste-heat from the automobile engine is very variable. However, the model is able also to estimate the waste heat available at the engine cooling loop, calculate the cooling capacity and monitor the temperature and humidity of the air at the cabin, as a function of the vehicle velocity, ambient temperature and sun radiation.

\section{Description of the on-board adsorption $\mathrm{A} / \mathrm{C}$ system}

Fig. 1(a) shows a picture of the on-board adsorption A/C system in the laboratory and fitted in a passenger vehicle Fig. 1(b). The system was designed and tested under the framework of Topmacs project for automotive air conditioning applications [18].
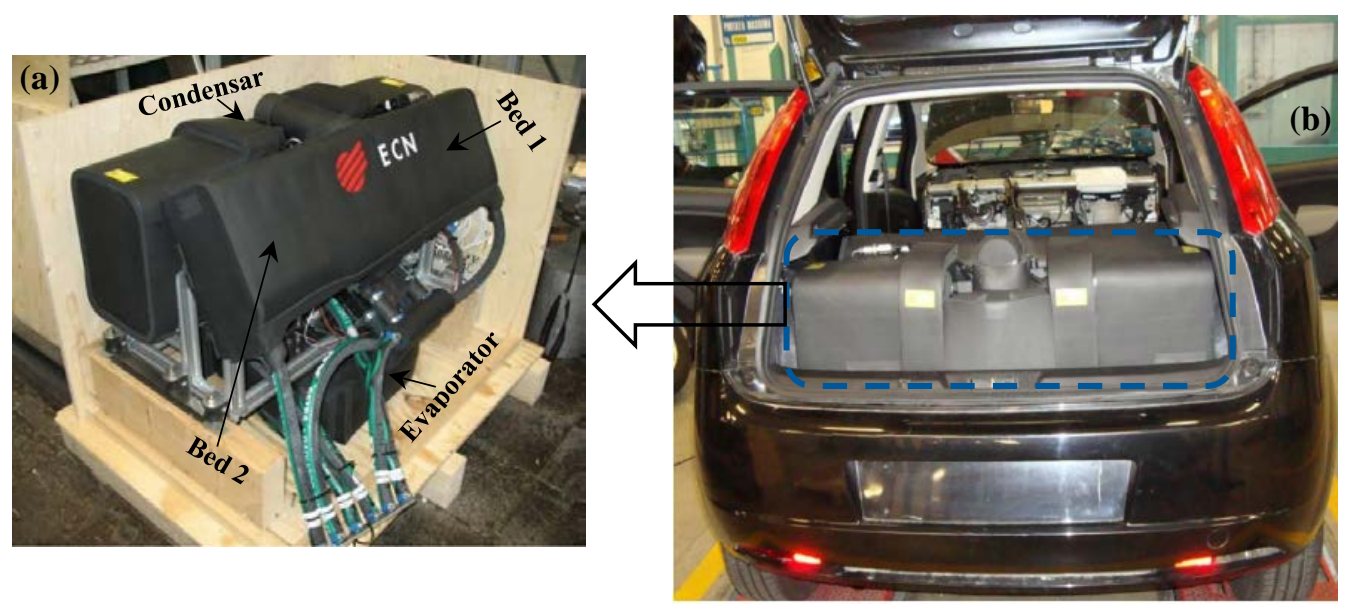

Fig. 1 Picture of the proposed on-board adsorption A/C chiller: (a) in the laboratory and (b) installed in the vehicle

A schematic diagram of the overall adsorption $\mathrm{A} / \mathrm{C}$ system implemented in the car is shown in Fig. 2(a), while the adsorption system layout with the main vehicle components is shown in Fig. 2(b). The system involves three secondary water loops, i.e. a water loop to cool the condenser and beds in series (Cooling Water Loop), a water loop to cool the air cabin (Chilled Water Loop) and a water loop to heat the beds (Heating Water Loop). 

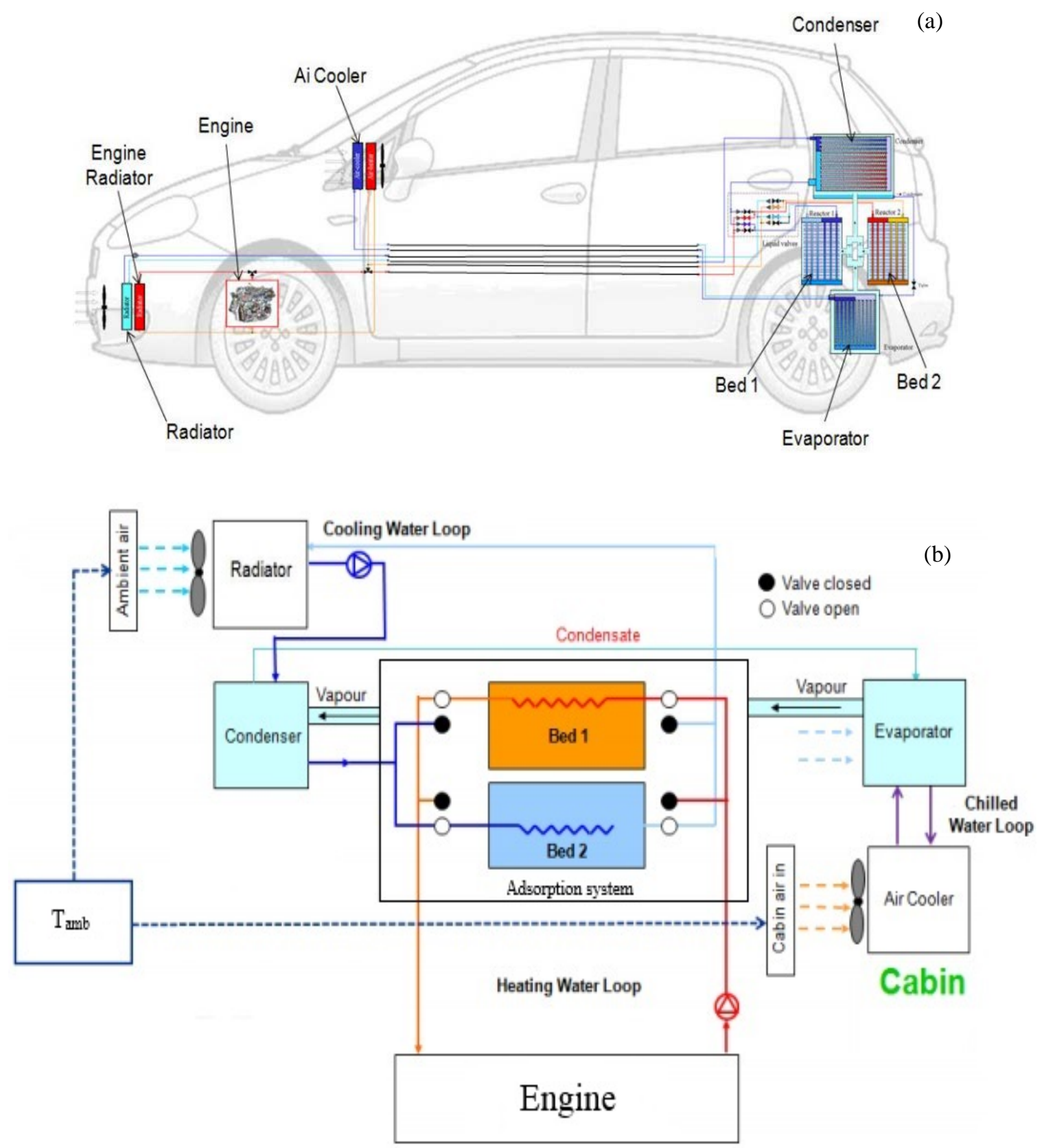

Fig. 2. a) Scheme of the on-board adsorption air conditioning system implemented in the car and b) layout of the on-board adsorption A/C system.

The system operation is cyclic. The heat from engine waste-heat is supplied to one of the beds to produce the desorption of the water vapor, at the same time the cooling water is 
provided to the other bed by the auxiliary cooler (radiator) using a hydraulic loop, which dissipates the heat to the environment. When Bed 2 is heated, the adsorbent starts to desorb the water vapor inside the bed. The pressure increases in the bed due to the water vapor and the valve between the bed and the condenser opens (the communication valve with the evaporator is kept closed). The water vapor condenses in the condenser, releasing its latent heat of condensation to the cooling water circuit. Liquid water passes from the condenser to the evaporator through an expansion valve. At the same time, the other bed (Bed 1) is being cooled down and starts to adsorb the water vapor. The pressure decreases in the bed, valves are all closed. When the pressure becomes lower than the one in the evaporator, the valve between the bed and the evaporator opens, and the bed starts to adsorb the water vapor coming from the evaporator, producing the evaporation of the water in it. During the evaporation stage, the water absorbs heat from the space to be conditioned, producing cooling effect which flows through the cabin cooler (Air Cooler). Then, the water from the auxiliary cooler is conducted to Bed 2, which is dry and hot, cooling it down, decreasing its pressure and activating the adsorption from the evaporator. At the same time, Bed 1, which is full and cooled, is heated up to increase its pressure and activate the desorption process.

The water flow rate available to activate the adsorption system is the same that normally goes through the radiator (Engine radiator) to cool down the engine. The engine needs to warm up as fast as possible in order to reduce emissions and increase the efficiency. During the warming up period there is no waste heat available. When the engine water temperature reaches an adequate level, the thermostat opens the cooling circuit to the engine radiator. The hot water is then sent to activate the adsorption system. This means that during the engine warm up no desorption can be carried out until the engine is sufficiently warm. Nonetheless, cooling the cabin is still possible provided that one or two beds have been kept dry, so that it can absorb vapor from the evaporator and produce a cooling effect from the beginning of a driving cycle.

The engine coolant system includes a thermostat which controls the engine temperature in order to first allow for the fastest warming up of the engine, and then just dissipate the 
excess heat on the engine radiator, therefore keeping constant the engine operating temperature. The engine radiator will be employed to dissipate the excess heat in the case that the adsorption system is not able to employ all the available waste heat in order not to overheat the engine. Additionally, a way to monitor the water temperature at the outlet of the adsorption system, and measures to ensure that it returns to the engine at an appropriate temperature have been implemented in the overall model. This corresponds to the constraints of engine design, which dictate a maximum acceptable temperature drop through the adsorption system in order not to decrease the engine operation temperature. This would negatively affect both engine efficiency and emissions.

\subsection{Testing facility}

In order to provide experimental data that will be used to feed the dynamic model of the overall system, several tests were performed on the on-board A/C system implemented in Fiat Grande Punto vehicle at the Centro Ricerche Fiat (CRF), Italy laboratories. Experimental tests were performed in a climatic chamber equipped with a roll bench as shown schematically in Fig. 3 to simulate the driving cycle under different start-up and ambient conditions. By performing these tests it was possible to define the amount of waste-heat in the engine cooling loop that can be recovered and transformed into cooling capacity by the adsorption system as well as to adjust the model of the cabin.

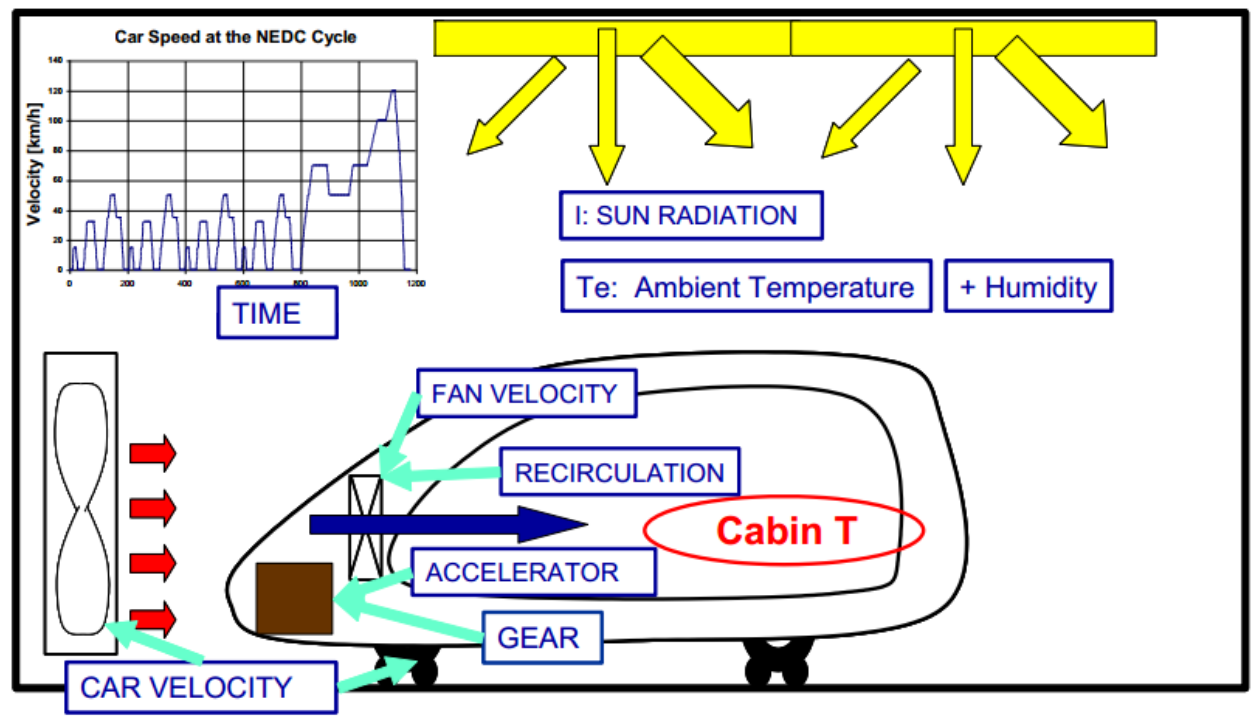


Fig. 3. Scheme of a climatic chamber with rolling bench suitable to perform the A/C assessment tests.

The assessment test follows the same routine as the usual $\mathrm{A} / \mathrm{C}$ characterization tests performed for cars:

- The vehicle is run on a roll test bench following a programmed standard driving cycle.

- The air is blown at the front of the vehicle in order to simulate ambient air around the vehicle on the road.

- Sun radiation is simulated with artificial lamps.

- Ambient temperature is kept at the desired condition.

- The A/C system is in operation following a standard procedure.

- Temperature of the air provided by the A/C system and temperatures at several positions of the cabin air are recorded during the tests. These measurements allow characterizing the thermal performance of the cabin and the A/C system.

\subsection{Testing cycle}

Fig. 4 shows the Normal European Driving Cycle (NEDC cycle) used as the testing cycle through the present study. In Europe, passenger vehicles are normally qualified in terms of fuel consumption using this particular type of cycle. The employed driving cycle is basically composed by two series of four repetitions of elementary urban cycles at low speed (ECE) separated by a higher speed extra urban cycle (EUDC), as it is shown in the figure.

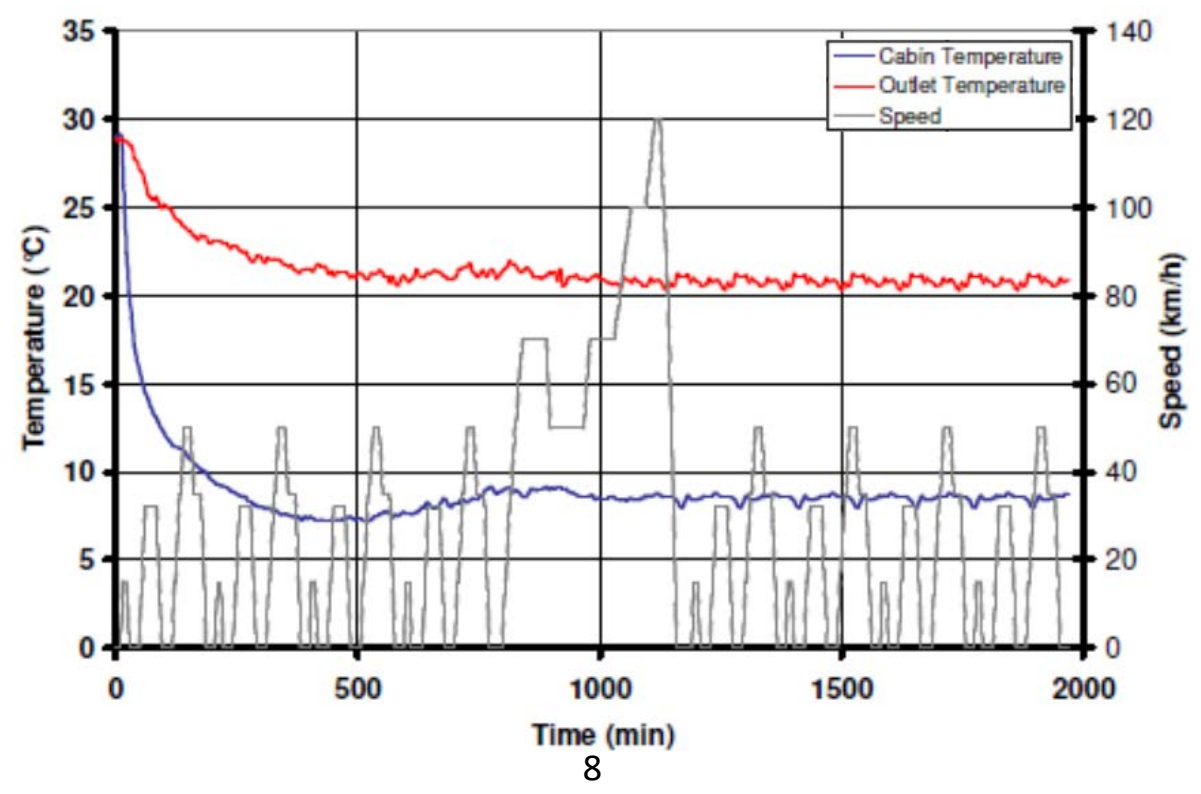




\section{Fig. 4. NEDC-2ECE cycle}

Under real driving conditions the available waste heat from the engine vary greatly. In addition, at the start-up (warming-up), no waste-heat is available to power the adsorption system until the engine has been warmed up, so the water is sent back to the engine. As shown in Fig. 4, the engine operation requirements make the input temperature and mass flow rate to the adsorption system quite variable and the conditions at the cabin are not constant either. The initial temperature is quite high and it drops as the cooling system starts to operate. This leads to a considerable variation of the temperature and humidity at the cabin until the comfort conditions are attained. Consequently, this variation is transmitted from the cabin to the evaporator and then to the beds.

\subsection{Start-up and ambient conditions}

Different start-up and ambient conditions have been simulated in order to assess and optimize the performance of the proposed on-board adsorption system. Table (1) shows the start-up conditions, while Table (2) presents the different ambient conditions which have been considered for the experimental and simulation tests.

Table 1 Start-up conditions

\begin{tabular}{|c|c|l|}
\hline $\begin{array}{c}\text { Start-up } \\
\text { condition }\end{array}$ & Assumptions & \\
\hline $\begin{array}{c}\text { Saturated } \\
\text { beds }\end{array}$ & $\begin{array}{c}\text { both beds are } \\
\text { saturated }\end{array}$ & $\begin{array}{l}\text { - All the valves of the system remain opened. } \\
\text { - The system is in equilibrium with the water stored at ambient temperature. } \\
\text { - The pressure is saturated and the uptake is at the equilibrium at that pressure and temperature. } \\
\text { - This strategy is the worst case scenario because it does not allow the system to produce cooling } \\
\text { effect at the driving cycle start. }\end{array}$ \\
\hline $\begin{array}{c}\text { One-dry } \\
\text { bed }\end{array}$ & $\begin{array}{c}\text { one of the } \\
\text { beds is dry }\end{array}$ & $\begin{array}{l}\text { - All the valves of the system are closed and isolated from the rest of the system. } \\
\text { - One bed remains with the maximum uptake and fully loaded with water, while the other bed } \\
\text { remains with the minimum uptake and dry, ready to adsorb water vapor when the valve connecting } \\
\text { the evaporator and the bed opens. } \\
\text { - This could only be possible if the valves communicating the beds with the condenser and } \\
\text { evaporator are able to practically seal the beds when closed. }\end{array}$ \\
\hline $\begin{array}{c}\text { Two-dry } \\
\text { beds }\end{array}$ & $\begin{array}{l}\text { both beds are } \\
\text { dry }\end{array}$ & $\begin{array}{l}\text { - All the valves of the system remain closed, therefore it is capable to maintain both beds } \\
\text { completely dry until the following driving cycle. } \\
\text { - After the use of the system during operation, the beds are dried with the remaining waste heat } \\
\text { stored in the engine, once the engine has been switched off. }\end{array}$ \\
\hline
\end{tabular}




\begin{tabular}{|l|l|l|}
\hline & $\begin{array}{l}\text { - This could only be possible if the valves communicating the beds with the condenser and } \\
\text { evaporator are able to practically seal the beds when closed. }\end{array}$ \\
\hline
\end{tabular}

Table 2 Thermal testing (ambient) conditions

\begin{tabular}{|c|c|c|c|c|c|}
\hline \multirow[b]{2}{*}{ Test } & \multicolumn{2}{|c|}{ Ambient conditions } & \multirow{2}{*}{$\begin{array}{l}\text { Driving } \\
\text { cycle }\end{array}$} & \multirow[b]{2}{*}{ A/C way of use } & \multirow[b]{2}{*}{ Remarks } \\
\hline & $\begin{array}{l}\text { Temp. } \\
{\left[{ }^{\circ} \mathrm{C}\right]}\end{array}$ & $\begin{array}{l}\text { R.H. } \\
{[\%]}\end{array}$ & & & \\
\hline $\begin{array}{c}\text { Test No. 1: Equivalent } \\
\text { European summer conditions }\end{array}$ & 28 & 50 & $\begin{array}{l}\text { NEDC } \\
\text { cycle }\end{array}$ & $\begin{array}{l}\text { Auto, with } 20^{\circ} \mathrm{C} \\
\text { internal set point }\end{array}$ & $\begin{array}{l}\text { Classify the } \mathrm{A} / \mathrm{C} \text { systems with regards to } \\
\text { fuel consumption and thermal comfort. }\end{array}$ \\
\hline $\begin{array}{c}\text { Test No. 2: Severe summer } \\
\text { conditions }\end{array}$ & 35 & 60 & $\begin{array}{l}\text { NEDC } \\
\text { cycle }\end{array}$ & $\begin{array}{l}\text { Auto, with } 23^{\circ} \mathrm{C} \\
\text { internal set point }\end{array}$ & $\begin{array}{l}\text { Considered for non-European countries, } \\
\text { where the thermal load is normally higher. }\end{array}$ \\
\hline Test No. 3: Cool-down test & 43 & 35 & $\begin{array}{l}\text { NEDC } \\
\text { cycle }\end{array}$ & $\begin{array}{l}\text { Auto, with } 25^{\circ} \mathrm{C} \\
\text { internal set point }\end{array}$ & $\begin{array}{l}\text { Severe European climate conditions during } \\
\text { the day. Cabin soaking temperature: } 63^{\circ} \mathrm{C} \text {. }\end{array}$ \\
\hline
\end{tabular}

\section{Mathematical modelling and system performance}

The non-equilibrium lumped parameter model and its validation procedures for the Sorbil $\mathrm{A} /$ water adsorption chiller prototype have been described in detail in the first part of this article [17]. The proposed model is used here to simulate the dynamic performance of the entire system at real driving conditions with different start-up and ambient conditions as shown in Table 1 and Table 2. The radiator and air cooler were modeled in a similar way as the condenser and evaporator presented in the first part of the paper [17]. Where, the heat exchangers were characterized by their overall thermal conductance (UA). A detailed analysis has been carried out and adequate values of UA for the radiator and air cooler, depending on water and air mass flow rates, have been estimated from experimental results provided by the (CRF).

The main structure of the overall model is shown in Fig. 5. The model systems exchange information through flows of different fluids and control parameters. Each system model is additionally composed by sub-models, representing the different subsystems included in it. 


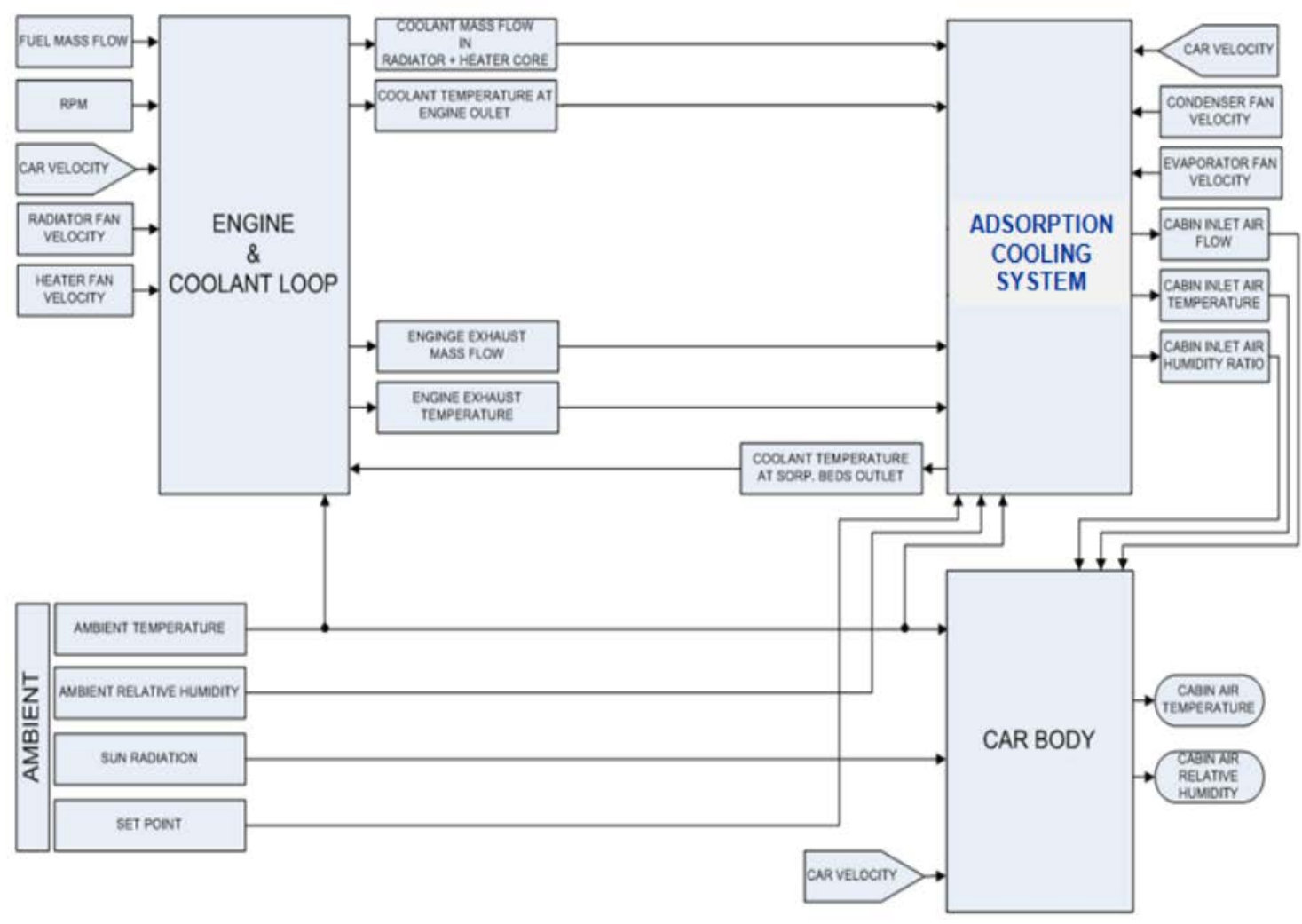

Fig. 5. Overall model structure

The different component models with the input data from Topmacs project [18] have been combined in the MATLAB Simulink environment, and have been integrated into the overall model. The inputs data to the overall model are the same as the inputs for a conventional A/C system during the assessment tests, which consist of: ambient temperature and humidity, A/C fan velocity, instantaneous power, engine speed (rpm), and finally, gear and accelerator position.

The settable operating conditions of heat transfer fluid temperatures and flow rates are shown in Table 3. The air flow rate values passing through the radiator and cabin cooler are taken from the experimental data given by CRF. 
Table 3. Nominal operating condition for the on-board adsorption system.

\begin{tabular}{|c|c|c|c|c|c|}
\hline \multicolumn{2}{|c|}{ Hot water inlet } & \multicolumn{2}{|c|}{$\begin{array}{l}\text { Cooling water inlet } \\
\text { (cond. + adsorber) }\end{array}$} & \multicolumn{2}{|c|}{ Chilled water inlet } \\
\hline $\begin{array}{l}\text { Temp. } \\
{\left[{ }^{\circ} \mathrm{C}\right]}\end{array}$ & $\begin{array}{c}\text { Flow rate } \\
{\left[\mathrm{kgs}^{-1}\right]}\end{array}$ & $\begin{array}{l}\text { Temp. } \\
{\left[{ }^{\circ} \mathrm{C}\right]}\end{array}$ & $\begin{array}{c}\text { Flow rate } \\
{\left[\mathrm{kgs}^{-1}\right]}\end{array}$ & $\begin{array}{l}\text { Temp. } \\
{\left[{ }^{\circ} \mathrm{C}\right]}\end{array}$ & $\begin{array}{c}\text { Flow rate } \\
{\left[\mathrm{kgs}^{-1}\right]}\end{array}$ \\
\hline 90 & 0.20 & 33 & 0.20 & 15 & 0.13 \\
\hline
\end{tabular}

\section{System performance}

The transient model is able to calculate the amounts of heat exchanged in each component, the performance of the system and consequently the air temperature inside the cabin. The cooling capacity of the system for the evaporator:

$\&_{\text {chill }}=\mathbb{R}_{\mathrm{w}, \text { chill }} \mathrm{Cp}_{\mathrm{w}} \int_{0}^{\mathrm{t}_{\text {cycle }}}\left(\mathrm{T}_{\text {chill, } \mathrm{i}}-\mathrm{T}_{\text {chill, }, \mathrm{o}}\right) \mathrm{dt}$

The condenser capacity:

$\&_{\text {cond }}=-1 \&_{\mathrm{w}, \mathrm{sec}} \mathrm{Cp}_{\mathrm{w}} \int_{0}^{\mathrm{t}_{\text {cyle }}}\left(\mathrm{T}_{\mathrm{sec}, \mathrm{i}}-\mathrm{T}_{\mathrm{sec}, 0}\right) \mathrm{dt}$

The heating capacity of the bed in desorption mode:

$\&_{\text {heat }}=1 \&_{h w, b} C p_{w} \int_{0}^{t_{\text {cycle }}}\left(\mathrm{T}_{\mathrm{hw}, \mathrm{i}}-\mathrm{T}_{\mathrm{hw}, \mathrm{o}}\right) \mathrm{dt}$

The cooling capacity of the bed in adsorption mode:

$\&_{\text {cool }}=-1 \&_{\mathrm{cw}, \mathrm{b}} \mathrm{Cp}_{\mathrm{w}} \int_{0}^{\mathrm{t}_{\mathrm{cydl}}}\left(\mathrm{T}_{\mathrm{cw}, \mathrm{i}}-\mathrm{T}_{\mathrm{cw}, \mathrm{o}}\right) \mathrm{dt}$

The COP of the system is defined as the ratio between the heat extracted by the evaporator and the heat source input to the bed.

$\mathrm{COP}=\frac{\&_{\text {chill }}}{\&_{\text {heat }}}=\frac{(\text { \& } \mathrm{Cp})_{\text {chill }} \int_{0}^{\mathrm{t}_{\text {cycle }}}\left(\mathrm{T}_{\text {chill,in }}-\mathrm{T}_{\text {chill,o }}\right) \mathrm{dt}}{(\text { \& } \& \mathrm{Cp})_{\text {des }} \int_{0}^{\mathrm{t}_{\text {cyde }}}\left(\mathrm{T}_{\mathrm{hw}, \mathrm{in}}-\mathrm{T}_{\mathrm{hw}, \mathrm{o}}\right) \mathrm{dt}}$

The performance of the adsorption chiller is mainly characterized by the cooling capacity of the system ( $\left.\dot{\mathrm{Q}}_{\text {chill }}\right)$ and by the coefficient of performance (COP). 


\section{Results and discussion}

\subsection{System optimization at constant operating conditions}

Optimizing the design and operating parameters of an adsorption system which has variable operating conditions becomes a considerably difficult task. Figs. 6(a,b) show the simulation results of the effect of adsorption/desorption cycle time variation on the average cooling capacity and COP at different ambient temperatures and constant engine coolant water value at $90^{\circ} \mathrm{C}$. The ambient temperatures values are assumed to correspond to the ones considered by CRF for the assessment tests shown in Table 2. The average cooling capacity and COP are calculated by the model as the average for the last cycle, once the system is operating in steady-state conditions and the initialization period does not have an effect over the performance anymore.
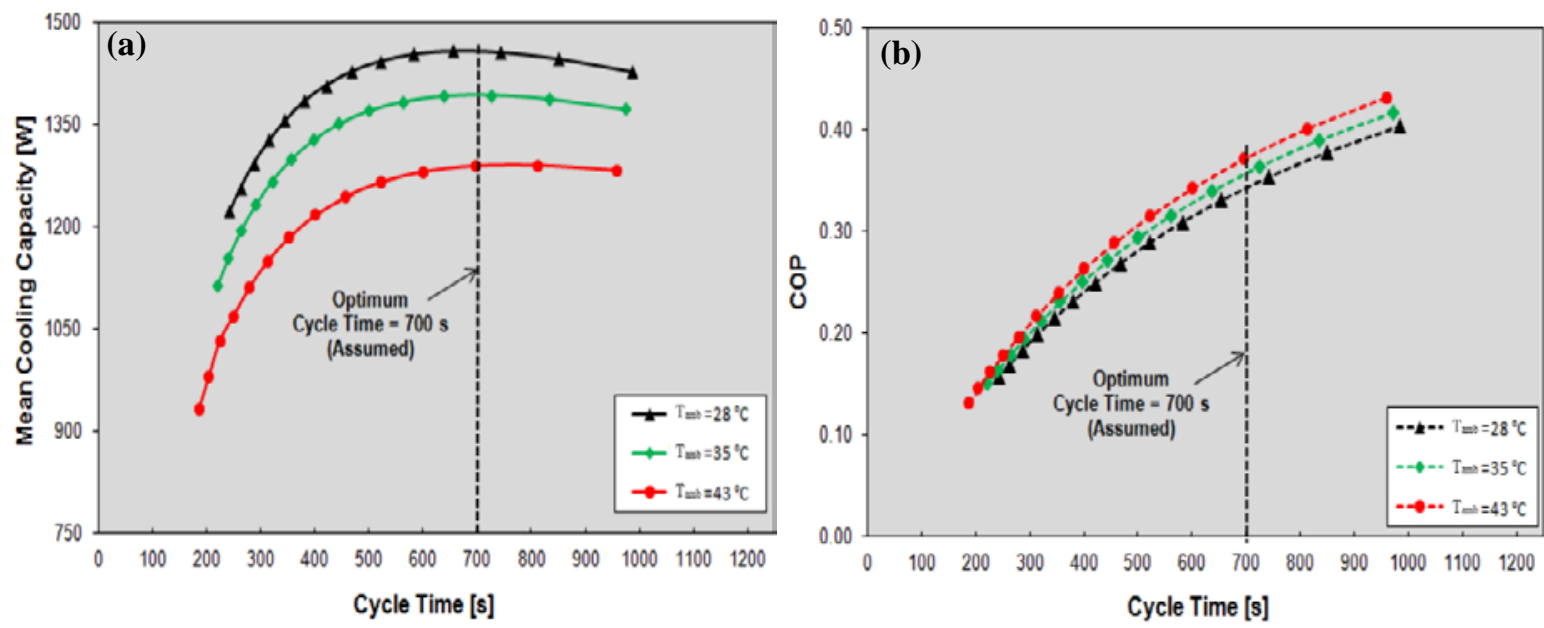

Fig. 6. Effect of adsorption/desorption cycle time on the system (a) Cooling capacity and

(b) COP

As it can be seen from Fig. 6(a), the highest values of the mean cooling capacity are obtained between 600 and 800 s cycle times. When cycle times are shorter than $400 \mathrm{~s}$ the cooling capacity decreases abruptly, and this is due to the fact that there is not enough time for adsorption or desorption to occur satisfactory. On the other hand, when cycle times are longer than $800 \mathrm{~s}$, the cooling capacity decreases gradually since adsorption tends to saturate as the adsorbent approaches to its equilibrium condition regardless of the cycle 
time employed. The COP increases uniformly as the cycle time increases, this is because the final part of the adsorption/desorption process increases the cooling produced but requires a longer time, and therefore the cooling capacity decreases.

In addition, it can be observed that the cooling capacity increases with decreasing ambient temperature. When the outdoor air temperatures are high (such as $43^{\circ} \mathrm{C}$ ), the cooling down of the bed is taking place at a higher temperature. This has a negative effect on the cooling capacity, since a less amount of water vapor is therefore adsorbed in the adsorbent bed. It can be said that the refrigeration effect will be improved when the system is operating at lower ambient temperatures since the cooling process of the beds will be more efficient, allowing faster cycling times. In contrast the COP decreases with decreasing ambient temperatures. This occurs because the system requires more engine waste energy to heat the adsorbent bed when working at lower ambient temperatures, since it will be more difficult to heat the bed after it has been cooled down at lower cooling temperatures. However, the impact of the cycle time on the COP is more significant than the ambient temperatures. When the ambient temperature drops from $43^{\circ} \mathrm{C}$ to $28{ }^{\circ} \mathrm{C}$, the cooling capacity increases from $1.29 \mathrm{~kW}$ to $1.46 \mathrm{~kW}$ and the COP decreases from 0.39 to 0.34 . On the other hand, the optimum cycle time maximizing the capacity increases from 656 to 812 s when the environmental temperature increases from 28 to $43^{\circ} \mathrm{C}$ as shown in Table 4 .

Table 4. Results of the cycle time optimization study.

\begin{tabular}{|c|c|c|c|c|}
\hline $\begin{array}{l}\mathbf{T}_{\mathrm{amb}} \\
{\left[{ }^{\circ} \mathrm{C}\right]}\end{array}$ & $\begin{array}{l}\text { Optimum Cycle Time } \\
\text { to maximize cooling } \\
\text { capacity } \\
{[s]}\end{array}$ & $\begin{array}{c}\text { Optimum Ad/Desorption } \\
\text { Time [s] }\end{array}$ & $\begin{array}{c}\text { Maximum Cooling Capacity } \\
{[[\mathrm{kW}]}\end{array}$ & COP \\
\hline 28 & 656 & 328 & 1.46 & 0.34 \\
\hline 35 & 726 & 363 & 1.39 & 0.36 \\
\hline 43 & 812 & 406 & 1.29 & 0.39 \\
\hline
\end{tabular}

Although the results obtained provide a guideline for the design and optimization of a control system aimed to provide the maximum cooling output at different operating conditions, it is apparent that an optimum value around $700 \mathrm{~s}$ for the cycle time (i.e. an 
ads/desorption time of 350 s) could make the system achieve a good performance for the whole range of ambient temperatures studied (from $28^{\circ} \mathrm{C}$ to $43^{\circ} \mathrm{C}$ ).

\subsection{System performance evaluation under different real driving conditions}

Different start-up and ambient conditions such as shown in Table (1) and Table (2) have been simulated under real driving conditions in order to assess the performance of the entire adsorption A/C system. For all the tests it is assumed that the A/C system is working in recirculation mode. This means that the inlet air temperature to the cabin cooler is at the cabin temperature, which will be decreasing with the time. This is the usual mode of operation for the A/C system in summer conditions.

The control strategy of the beds implemented in the overall model was based on a fixed adsorption/desorption cycle time of 350 s corresponding to the optimum value obtained from the parametric studies presented in Sub-section (5.1). This means that the adsorption/desorption cycle will be reversed when it reaches a settable value which is 350 s. However, the simulation results showed a poor performance when a fixed cycle time was implemented in the model. This happened because the bed could not be heated up efficiently once the bed temperature at the end of the cycle was not close to $90{ }^{\circ} \mathrm{C}$, and as a consequence the system could not adsorb enough vapor. This fact negatively affected the system performance. Therefore, a different bed control strategy was implemented which was not only based on the cycle time but also on the maximum temperature of the bed. This strategy is based on a double condition: the cycle will be reversed when the bed in heating mode reaches at least $85^{\circ} \mathrm{C}$, and the cycle time reaches at least its optimum value (350 s). The results obtained showed a good operation of the system so this double condition was implemented in the overall model for all assessment tests.

\subsubsection{Test No. 1: Equivalent European summer conditions}

Figs. 7(a-d) show the simulation results obtained at the equivalent European summer conditions (Test No. 1) and start-up conditions for both beds being completely dry (Twodry beds). 

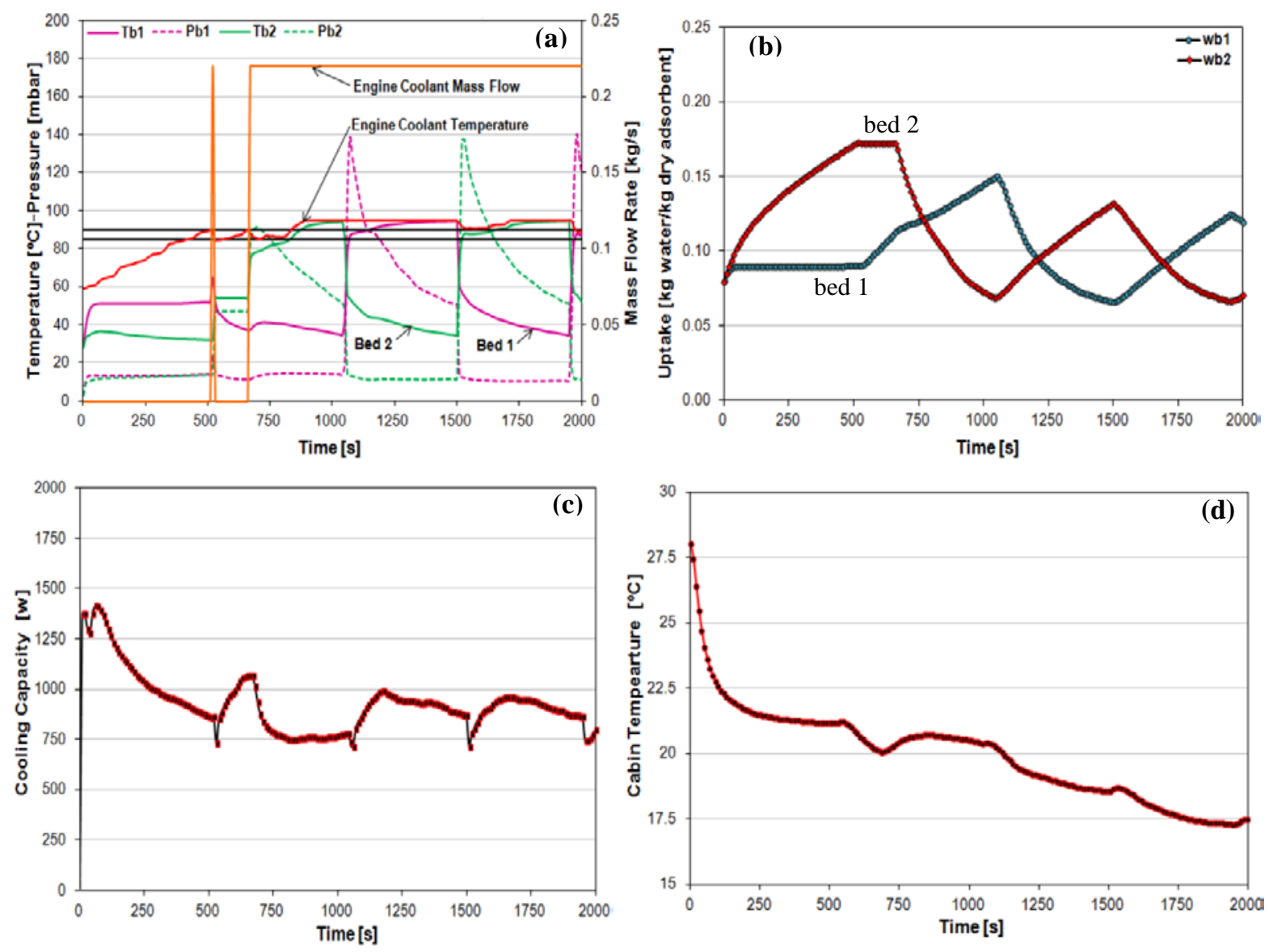

Fig. 7. Equivalent European summer conditions with Two-dry beds: (a) Temperature and pressure profiles of bed 1 and bed 2, engine coolant temperature and mass flow rate, (b) water content (uptake) in two beds, (c) cooling capacity, and (d) cabin temperature

Fig. 7(a) shows the variation in temperature and pressure profiles in the adsorbent beds with the time (0:2000 s). As discussed previously, the available waste heat from the engine under real driving conditions is very variable, especially during the engine warming up period. In the first approximately $660 \mathrm{~s}$ after engine start-up, the outlet coolant temperature of the engine is below $90{ }^{\circ} \mathrm{C}$, so it is not possible to use the engine coolant water as a heat source for the adsorption system. At $550 \mathrm{~s}$ there is a first activation peak and the engine coolant temperature reach $90{ }^{\circ} \mathrm{C}$ for the first time. However, the bed is very cold and absorbs a lot of heat, producing a sudden drop of the engine coolant temperature. Consequently, the thermostat which controls the engine coolant flow to be used by the system is switched off, causing a deactivation of the adsorption system. After $660 \mathrm{~s}$, the 
adsorption system is activated again and is able to use the waste energy from the engine coolant at temperature between $85-90{ }^{\circ} \mathrm{C}$, until time reaches $850 \mathrm{~s}$. After the $850 \mathrm{~s}$, the engine outlet coolant temperature goes above $90{ }^{\circ} \mathrm{C}$, insuring high engine efficiency. The adsorption system is then able to use the engine coolant as a higher temperature heat source, which lies between $90-95^{\circ} \mathrm{C}$. After the car operates in full constant driving conditions, the engine is able to provide the amount of hot water at almost constant flow rate along the rest of the driving cycle and the adsorption-desorption cycles become steady.

The water content of the adsorbent beds is shown Fig. 7(b). During the first half cycle time (360 s), bed 1 being heated up, the adsorbent in bed 1 is in desorption mode and the water content decreases to about $0.07 \mathrm{~kg} / \mathrm{kg}$ of Silica-gel. At the same time, bed 2 is being cooled, the adsorbent in bed $\mathbf{2}$ is in adsorption mode and the water content of the adsorbent is increased (adsorbing water vapor from the evaporator) to about $0.14 \mathrm{~kg} / \mathrm{kg}$ of Silica-gel. The adsorbents exchange their roles in the next $360 \mathrm{~s}$ in the third cycle. When bed 2 almost reaches equilibrium conditions, at $520 \mathrm{~s}$ after the engine start-up, the cycle is reversed, bed $\mathbf{1}$ then starts to adsorb since it is dry and empty of water, and bed $\mathbf{2}$ starts to desorb as it is fully loaded with water. For the last stable cycle (from $1500 \mathrm{~s}$ to $1950 \mathrm{~s}$ ) the uptake variation ranges from $6.5 \%$ to $13 \%$.

Simulation results of the produced cooling capacity with time is shown in Fig. 7(c). It is clear that the cooling capacity changes with time and the system is able to produce a cooling effect from the beginning. In this case, the heat from the engine is not needed to start producing cooling since the beds are assumed to be initially dry. In this way, once one of them is cooled down and connected to the evaporator, it starts to adsorb and produces a cooling effect immediately. This start-up strategy is the best case scenario since it allows the production of cooling since the beginning of the driving cycle without the necessity of the engine coolant temperature to reach $90^{\circ} \mathrm{C}$. At steady state conditions, the adsorption system is able to produce an average cooling capacity of about $925 \mathrm{~W}$.

Fig. 7(d) shows the change in cabin temperature with the time. As shown in the figure, the proposed system is able to cool down the cabin very fast, achieving a quite low temperature 
in the cabin. The cabin temperature decreases during each cooling cycle and slightly increases during the reversing period, this is due to heat transferred from the cabin to the inner air. However, the system is able to decrease the cabin temperature from $28^{\circ} \mathrm{C}$ to 17.5 ${ }^{\circ} \mathrm{C}$ during $2000 \mathrm{~s}$, depending on the test. In real case, the cabin thermostat would switch off the system once the comfort temperature $\left(20^{\circ}\right)$ has been reached.

Figs. 8(a-b) show the simulation results for the tests at the equivalent European summer conditions (Test No. 1) and different start-up conditions: one-dry bed, Two-dry beds and saturated beds.
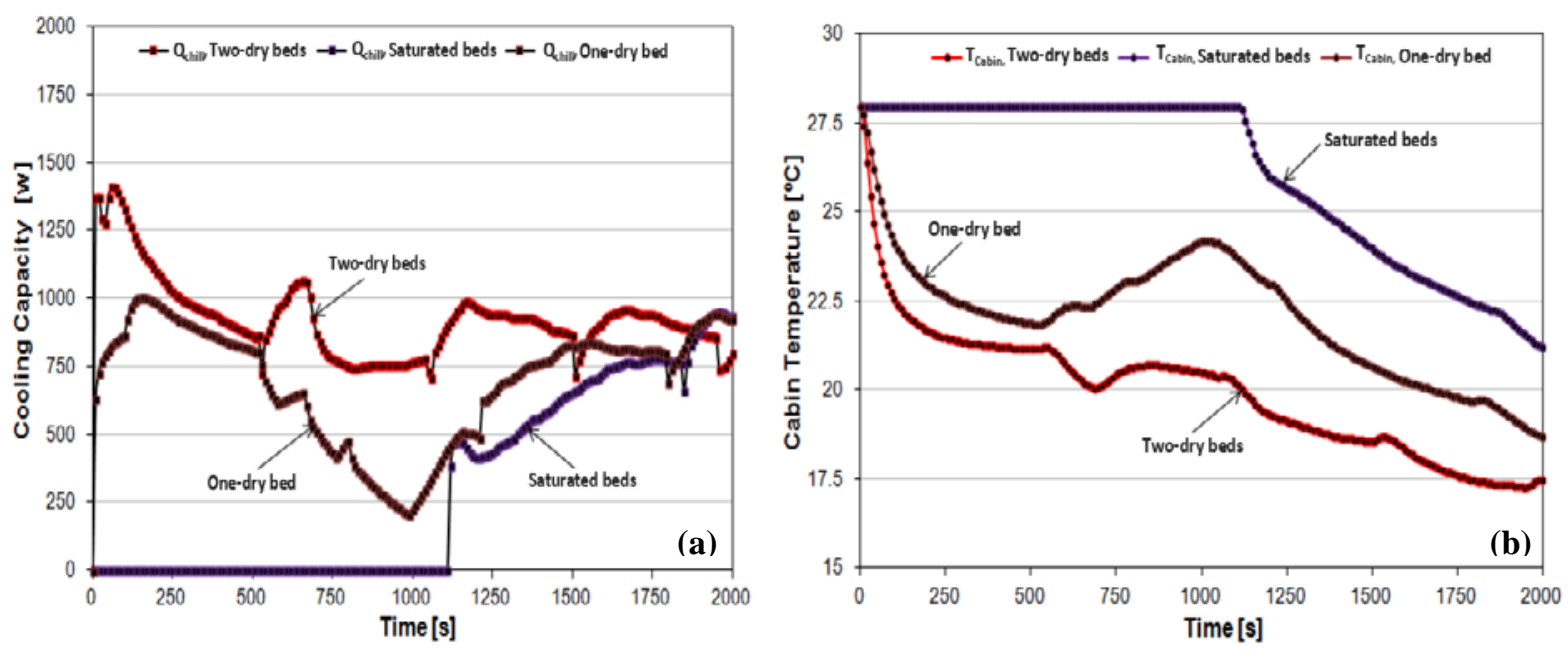

Fig. 8. Equivalent European summer conditions (Test No. 1) and different start-up strategies: (a) Cooling capacity and (b) Cabin temperature

As shown in Fig. 8(a) at the beginning, the system with two beds saturated takes a long time to start producing a cooling effect (around 1100 s), while with one bed dry it is possible to have cooling production since the beginning of the driving cycle with about 500 $\mathrm{W}$. In the case of both beds initially dry, the system is able to produce a higher cooling effect, and therefore a faster decrease of the cabin temperature. Nevertheless, the difference between having one or two beds dry is not so important. This indicates that in order to have good performance it would only be necessary that, after the engine is switched off, one of the beds is dried and sealed. The system with one dry bed is able to produce a mean cooling capacity of $700 \mathrm{~W}$, while with two dry beds is able to produce a mean cooling capacity of 
$925 \mathrm{~W}$, and with both beds saturated it is able to produce a mean cooling capacity of 300 W. In one-dry bed and two-dry beds start-up conditions the system is able to reach a cabin temperature lower than $20{ }^{\circ} \mathrm{C}$ which is the comfort temperature, Fig. 8(b). Keeping both beds dry results in more efficiency for the system performance, and also the comfort conditions are reached quicker.

\subsubsection{Test No. 3: Cool-down test}

Figs. 9(a-d) show the results obtained for the cool-down test (Test No. 3) with the better start-up condition case (Two-dry beds) with the time. The cool-down test is the most severe test of all studied tests, the ambient temperature is $43^{\circ} \mathrm{C}$ and $35 \% \mathrm{RH}$. They has a highly severe conditions for the thermal compressor, where the initial cabin temperature is higher due to soaking $\left(46{ }^{\circ} \mathrm{C}\right)$. Therefore, the performance of the system drastically deteriorates.

As can be seen from Fig. 9(a), due to the characteristics of the cool-down test, the adsorption-desorption cycles are more stable in comparison with the results obtained previously for Test No. 1. At the cool-down test, the car is in highway driving mode, which guarantees that a more constant engine coolant mass flow rate feed the adsorption system. Furthermore, the cycle time is shortened since the system performs at higher cooling temperature, so that it tends to follow quite fast adsorption-desorption cycles, and the range of uptake variation becomes very small as shown on Fig. 9(b). As a consequence, the number of cycles per driving cycle and their frequency increase, which leads to a slight increase of the cooling capacity. Thus, the system is able to produce a mean cooling capacity of approximately $1.1 \mathrm{~kW}$, Fig. 9(c).

Nevertheless, due to the high severe conditions, the cooling effect produced by the system is not enough to carry the cabin temperature to comfort conditions $\left(25^{\circ} \mathrm{C}\right)$. The cabin temperature is about $37^{\circ} \mathrm{C}$ as shown in Fig. 9(d). However, increasing the cycle time and modifying the switching criterion can improve the operation. 

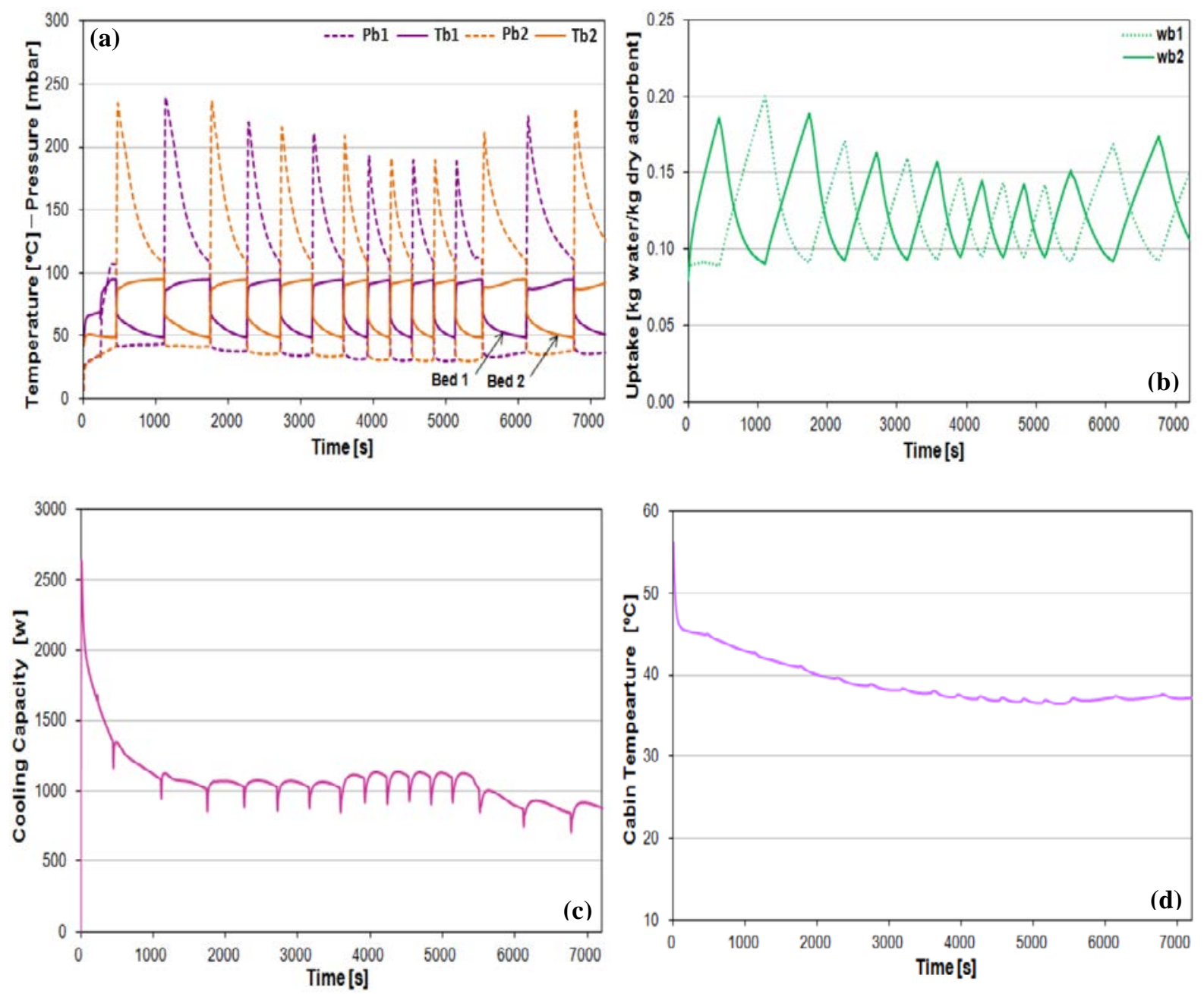

Fig. 9. Cool-down (Test No. 3) with Two-dry beds start-up conditions: (a) Temperature and pressure profiles of bed 1 and bed 2, (b) water content in two beds, (c) cooling capacity, and (d) cabin temperature

\subsection{System performance comparison at different test conditions}

Table 5 summarizes the system performances obtained at different operating conditions for the best start-up scenario (Two-dry beds). The table shows the different ambient conditions ( $\left.\mathrm{T}_{\mathrm{amb}}\right)$ with comfort temperatures $\left(\mathrm{T}_{\text {comf }}\right)$, cabin temperatures $\left(\mathrm{T}_{\mathrm{cab}}\right)$, cooling capacity $\left(\dot{Q}_{\text {chill }}\right)$ and corresponding COP. 
Table 5. System performance at different operating conditions and Two-dry beds start-up condition.

\begin{tabular}{|c|c|c|c|c|c|c|}
\hline \multirow[b]{2}{*}{ Test } & \multicolumn{2}{|c|}{ Ambient conditions } & \multirow[b]{2}{*}{$\begin{array}{l}\mathbf{T}_{\text {comf }} \\
{\left[{ }^{\circ} \mathbf{C}\right]}\end{array}$} & \multirow[b]{2}{*}{$\begin{array}{l}\mathbf{T}_{\text {cab }} \\
{\left[{ }^{\circ} \mathbf{C}\right]}\end{array}$} & \multirow[b]{2}{*}{$\begin{array}{l}\dot{\mathbf{Q}}_{\text {chill }} \\
\text { [W] }\end{array}$} & \multirow[b]{2}{*}{ COP } \\
\hline & $\begin{array}{l}\mathbf{T}_{\mathrm{amb}} \\
{\left[{ }^{\circ} \mathrm{C}\right]}\end{array}$ & $\begin{array}{l}\text { R.H } \\
\text { [\%] }\end{array}$ & & & & \\
\hline Test No. 1: Equivalent European Summer Conditions & 28 & 50 & 20 & 17.5 & 925 & 0.40 \\
\hline Test No. 2: Severe Summer Conditions & 35 & 60 & 23 & 24.4 & 930 & 0.42 \\
\hline Test No. 3: Cool-down & 43 & 35 & 25 & 37 & 1100 & 0.44 \\
\hline
\end{tabular}

As can be shown, for the Equivalent European Summer Conditions (Test No. 1), the adsorption cooling system is able to deliver a refrigeration capacity of $925 \mathrm{~W}$ with a COP of 0.40 . The final cabin temperature is obtained $17.5{ }^{\circ} \mathrm{C}$, which means that comfort conditions $\left(20^{\circ} \mathrm{C}\right)$ can be perfectly achieved. For Test No. 2 (Severe Summer Conditions), a mean cooling capacity of $930 \mathrm{~W}$ with COP of 0.42 was obtained. Under these conditions, the system is able to produce a reasonable cooling effect but not enough to carry the cabin temperature to comfort conditions (target value $23{ }^{\circ} \mathrm{C}$ ), and is only able to keep the cabin at around $24.4^{\circ} \mathrm{C}$. For the most severe of all assessment tests (Test No. 3), the system is able to produce a mean cooling capacity of $1100 \mathrm{~W}$ with a COP of 0.44 . The cooling effect produced by the system is not enough to carry the cabin temperature $\left(37^{\circ} \mathrm{C}\right)$ to comfort conditions (target value $25^{\circ} \mathrm{C}$ ). It can be observed that under severe conditions the COP of the system tends to increase. This is simply due to the fact that the system performs at a higher cabin temperature, which leads to an increase of the evaporation temperature.

\subsection{Design modification of the on-board system layout using two radiators}

In order to further increase the system performance, a new system layout with two independent cooling loops (two radiators) has been investigated as alternative to the reference system shown Fig. 2b. The only difference between this system layout and the previously analysed is the number of radiators. Instead of using one radiator to cool in series the condenser and then the adsorbent bed, the new proposed system comprises of two radiators working in independently cooling loops, in which one radiator is used to cool down the bed and another is used to cool down the condenser as shown in Fig. 10. 


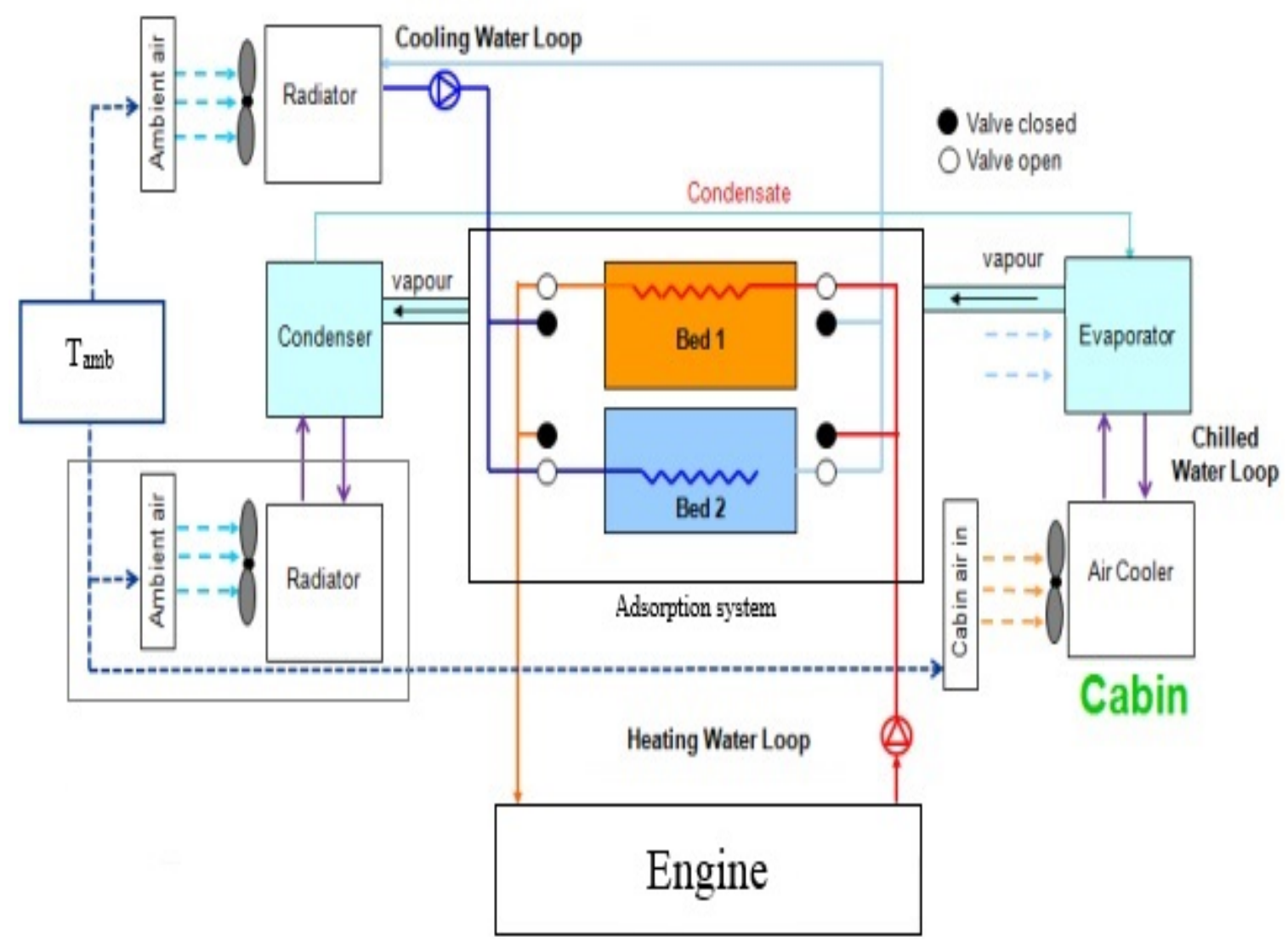

Fig. 10. Scheme layout of the proposed alternative system configuration of the onboard adsorption A/C system.

\subsubsection{Performance evaluation of the alternative system layout}

Figs. 11(a,b) present the simulation results of the proposed alternative layout system compared with the results of the reference system. The comparison is based on a constant engine coolant water temperature at $90{ }^{\circ} \mathrm{C}$ and Equivalent European summer conditions ( $\mathrm{T}_{\mathrm{am}}=28{ }^{\circ} \mathrm{C}$ and $50 \%$ R.H).

The simulation results showed that the alternative layout system has logically a better system performance. The maximum cooling capacity increased by 12.3\% (from 1.46 to $1.64 \mathrm{~kW}$ ) and the optimum cycle time decreased by $28.4 \%$ (from 656 to $511 \mathrm{~s}$ ) compared to the reference system layout. The cooling of the beds for the alternative layout system takes place at lower temperature, allowing faster cycling times and better performance. In contrast, in the original system layout, the cooling water enters the bed at higher 
temperature since it has previously absorbed heat from the condenser, consequently, less amount of water vapor will be adsorbed by the bed. This negatively affects the performance of the system.
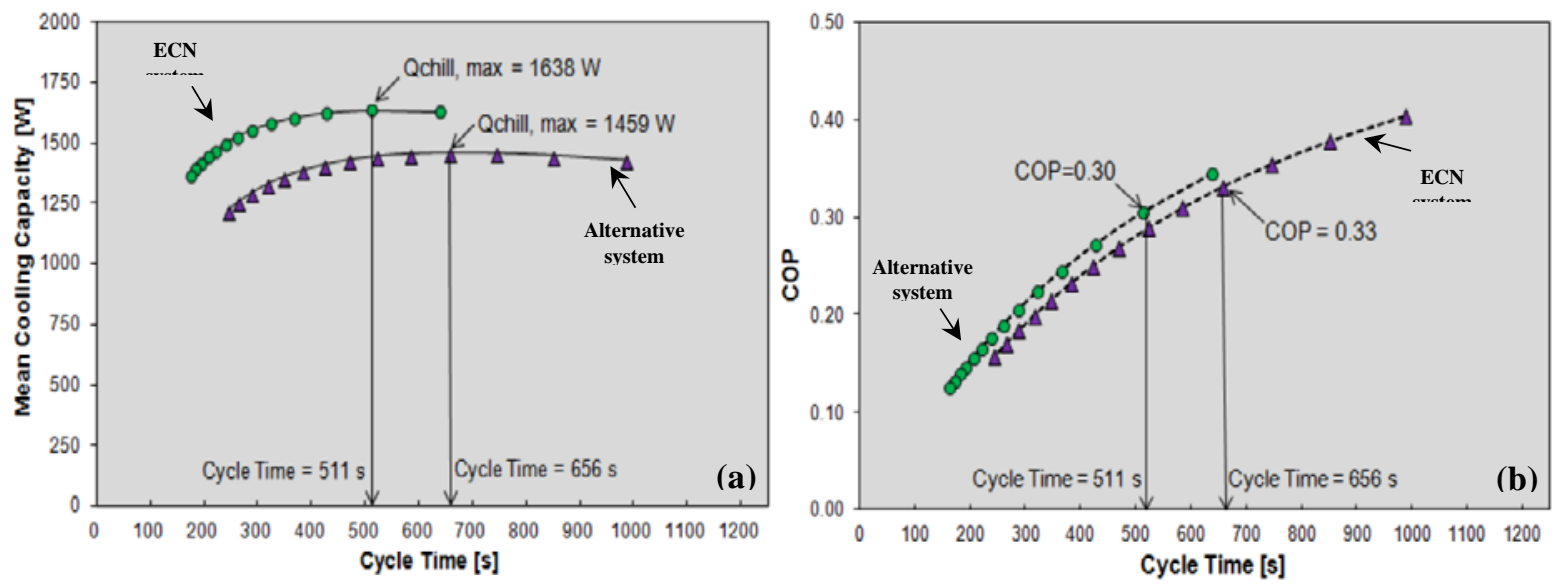

Fig. 11. Effect of cycle time on the system performance for different system layouts: (a) Cooling Capacity and (b) COP.

Interestingly, COP is slightly decreased by $9.1 \%$ with the alternative layout. This occurs because the system requires more engine waste energy to heat the sorption bed when working at lower cooling temperatures. This happens as it will be more difficult to heat the bed after it has been cooled down at lower cooling temperatures in the cycle time which maximizes the cooling capacity.

Figs. 12(a,b) shows the variation of the bed inlet $\left(\mathrm{T}_{\mathrm{hw}, \mathrm{i}}\right)$ and outlet heating $\left(\mathrm{T}_{\mathrm{hw}, \mathrm{o}}\right)$ water temperatures and inlet $\left(\mathrm{T}_{\mathrm{cw}, \mathrm{i}}\right)$ and outlet $\left(\mathrm{T}_{\mathrm{cw}, \mathrm{o}}\right)$ cooling water temperatures with cycle time for the original and alternative system layouts. From the results obtained, when using the proposed alternative layout system, the inlet cooling water temperature slightly deceases from 37.6 to $36^{\circ} \mathrm{C}$ (at the optimum cycle time). The cooling water entering the bed in the original layout absorbs first the heat from the condenser, coming back to the bed at a higher temperature. In addition, the difference between the inlet and outlet cooling water temperature is larger, which means that the bed is being cooled more efficiently and it takes 
shorter time to cool down. Consequently, the cycle time is shorter in comparison with the original layout.
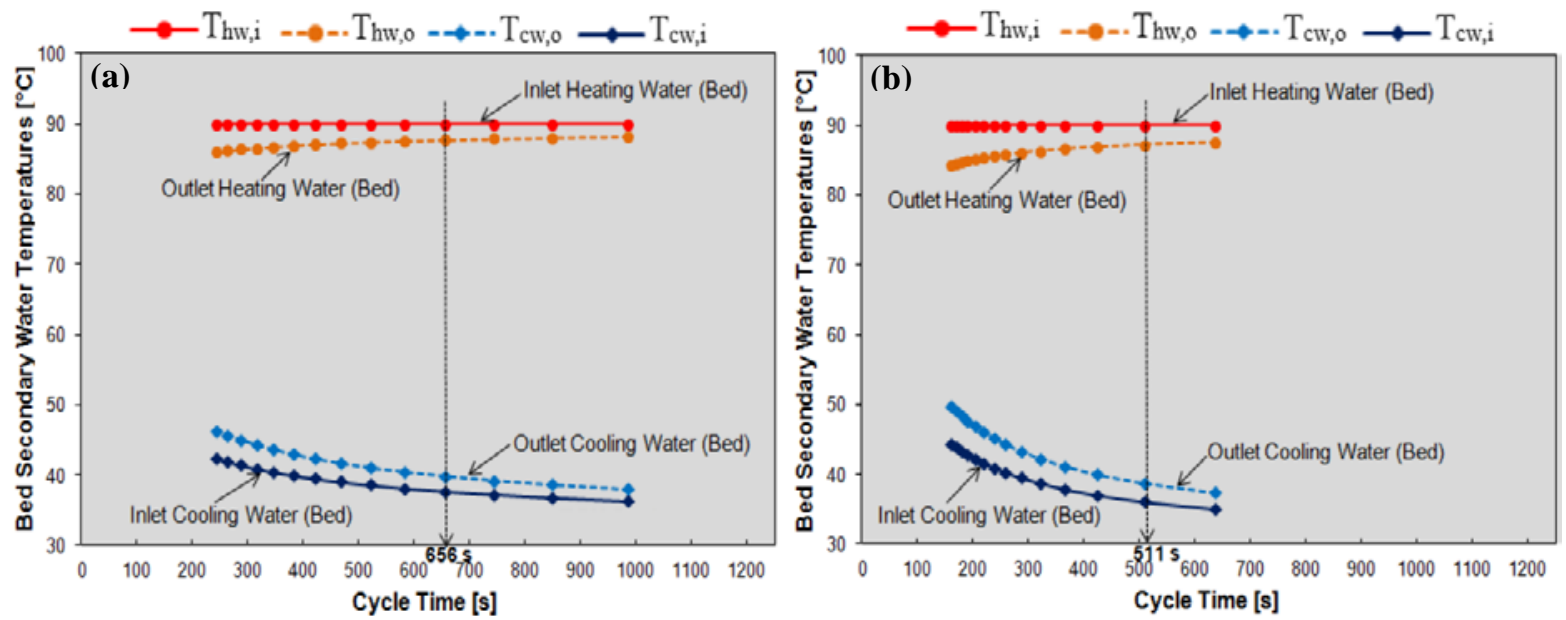

Fig. 12. Variation of the bed heating and cooling water temperatures with cycle time for different system layouts: (a) Original system design and (b) Alternative system design.

Figs. 13(a,b) show the variation of the condenser, evaporator, chiller and secondary fluids temperatures with the cycle time for both the original and the alternative layouts.
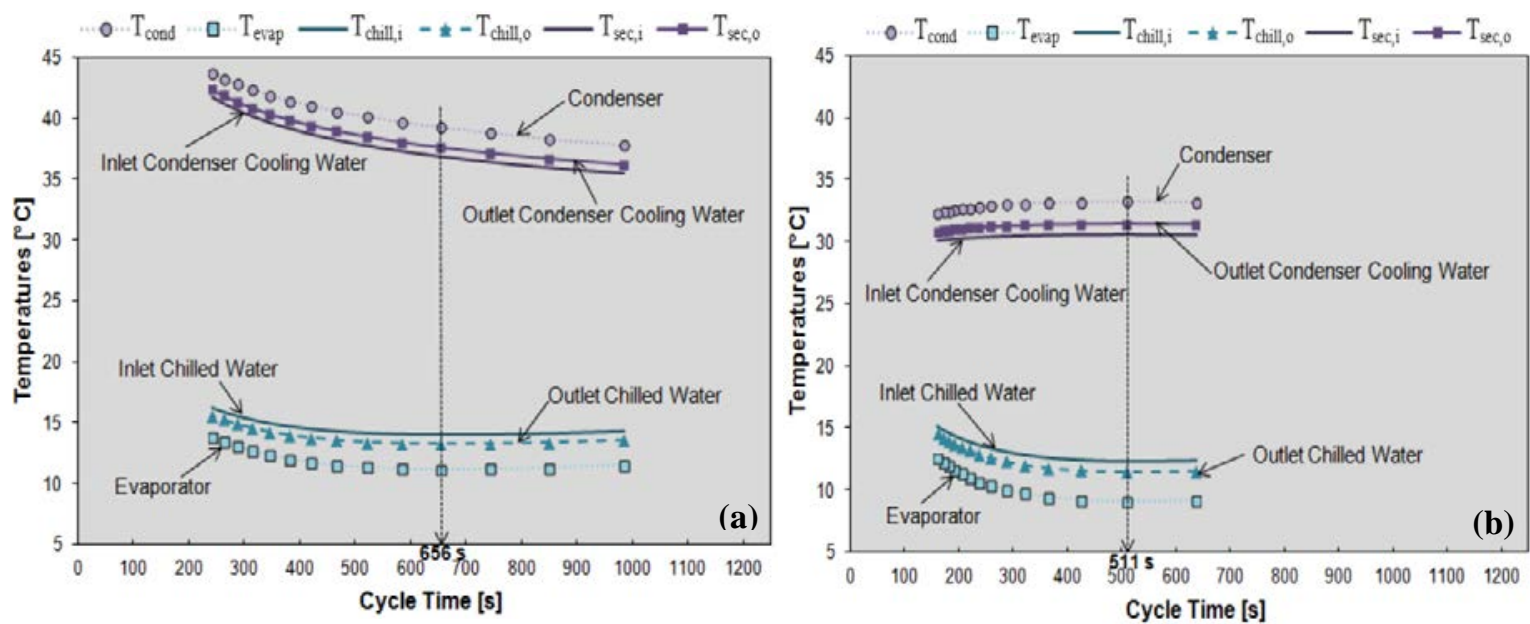

Fig. 13. Variation of the evaporator and condenser secondary water temperatures with cycle time for different system layouts: (a) ECN system design (b) Alternative system layout 
The simulation results showed that, with the alternative layout system (two independent cooling loops) the inlet condenser cooling water temperature decreases from 36.86 to 30.59 ${ }^{\circ} \mathrm{C}$ and as a consequence the condenser temperature decreases from 39.24 to $33.26{ }^{\circ} \mathrm{C}$ compared to the ECN system layout. The condenser is obviously able to reject more heat, in turn improving the system performance. In the original layout, the cooling water entering the condenser first absorbs the heat from the bed coming back to the condenser at higher temperature. Moreover, the chilled water temperature entering the evaporator decreases from 14 to $12.3^{\circ} \mathrm{C}$ and the evaporator temperature decreases from 11 to $9{ }^{\circ} \mathrm{C}$ when having two independent cooling loops instead of one. When having a single cooling water loop, the refrigerant comes from the condenser to the evaporator at a higher temperature, which results in an increase of the evaporator temperature. Also, it absorbs less amount of vapor from the evaporator since it is more difficult to cool down the bed. Consequently, the evaporator pressure increases. This negatively affects the overall performance of the system.

\subsection{Effect of the alternative layout system on the system performance}

The possibility of employing two independent cooling loops with two radiators to enhance the performance of the adsorption $\mathrm{A} / \mathrm{C}$ system has been considered as an option at the beginning of the Topmacs project [18]. However, the decision was made not to proceed with this option, since it would increase the complexity of the on-board system in terms of size and cost. Despite this, the overall model has been built in such a way that it is possible to test different layouts and therefore it was decided to study this possibility as well.

Figs. 14(a,b) shows a comparison between the ECN system and the alternative system layout in terms of cooling capacity and the produced cabin temperatures. The tests performed at the Equivalent European summer conditions (Test No. 1) for the most favorable start-up condition (two-dry beds). 

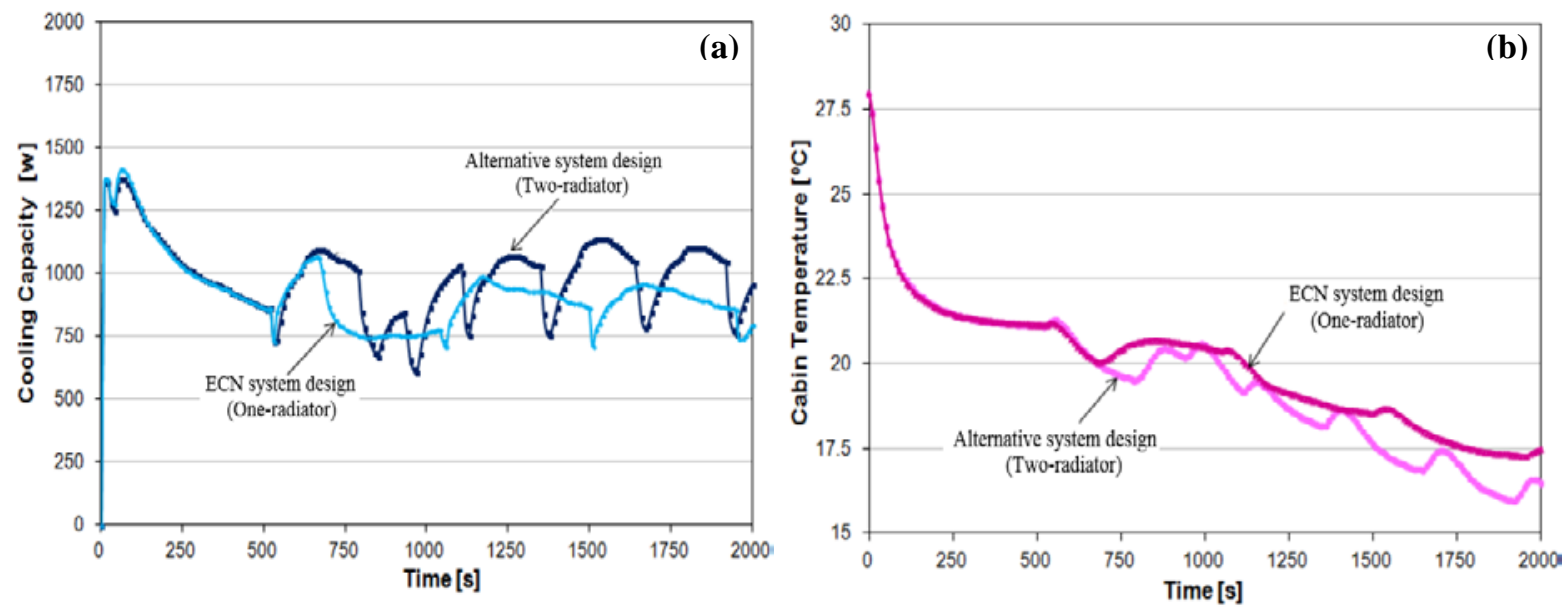

Fig. 14. Performance of the system at Equivalent European summer conditions (Test No. 1) and two-dry beds start-up strategies for different system layouts: (a) Cooling capacity and (b) Cabin temperature

The results shown that, the system with two radiators has a higher performance than that of one radiator. Using the alternative layout system instead to the ECN system layout, the average cooling capacity increased by $7.0 \%$ (from 925 to $990 \mathrm{~W}$ ) and the cabin temperature decreased by $9.1 \%$ (from 17.5 to $16{ }^{\circ} \mathrm{C}$ ) but the COP decreased by $25 \%$ (from 0.40 to 0.30). This happens because in the case of using the same radiator to cool the condenser and then the bed in series, it becomes more difficult to cool down the beds with water coming from the condenser at a higher temperature. As a consequence, a less amount of water vapor is adsorbed, resulting in a lower refrigeration effect. On the contrary, when using two radiators to cool down the bed and another is used to cool down the condenser, the COP decreases. This happens due to the fact that the system using two radiators performs at a lower evaporation temperature due to a decrease of the cabin temperature. The COP is very sensitive to the evaporation temperature. However, it is clear that using two independent radiators is more efficient, leading to better performance in terms of cooling capacity and cabin temperature. However, the difference is not high, and whether this option is cost effective or not would depend on the increase of the cost to include the second radiator. 


\section{Conclusions}

In this two part study, an improved dynamic model was developed to predict the performance of an adsorption system for automotive air-conditioning. In the first part, Part I, the model was validated against the experimental data and the results showed an excellent agreement. In the second part, Part II, the validated model was used to predict the transient performance and cabin temperature of the system when implemented in a car under real driving and different ambient conditions. The on-board A/C system was driven by wasteheat from the engine coolant loop. Results showed that, after the car operates in full constant driving conditions, the engine is able to provide the amount of hot water at almost constant flow rate along the rest of the driving cycle and the adsorption-desorption cycles become steady. The proposed system is able to deliver an average cooling capacity of about $925 \mathrm{~W}$ with COP of 0.40 and a cabin temperature of $17.5^{\circ} \mathrm{C}$ at Equivalent European summer conditions. However, the system is not able to reach the target temperature with more sever ambient conditions. An alternative system layout with two independent cooling loops (two radiators) was proposed in order to increase the system performance. The obtained results showed that, the proposed system layout has a higher cooling capacity but of course it requires an extra radiator and the system complexity increases.

In regard to the start of the system, it is clear that in order to have cooling effect from the beginning of the driving, at least one bed should be dried and sealed in a way that it is able to adsorb vapor from the very beginning of the cycle. Otherwise, taking into account the necessary time for the engine warming up and the variability of the waste energy after that moment, the starting of the cooling would take a considerable time. Keeping both beds dry would of course allow a higher cooling capacity. However this would require a longer drying period at the end of the driving cycle, another sealing valve, and a more complex control system when the extra cooling provided is not so much. From the obtained results, one bed dried seems the best design compromise. At moderate thermal loads the designed system is able to provide enough cooling capacity and is able to decrease the cabin temperature below the comfort temperature in a reasonable time. Under high thermal load, as for instance, under soak conditions, the system seems to be still undersized although it is still able to significantly decrease the cabin temperature from its very high initial value. 
The amount of waste-heat available in the engine coolant loop seems sufficient to drive the adsorption system and to produce enough cold to keep comfortable temperatures in the cabin. The model is able to run under the extreme variable conditions of a real driving cycle and capture the complex dynamics of the whole system.

\section{Acknowledgements}

This work has been partially supported by the Thermally Operated Mobile Air Conditioning Systems (TOPMACS). The authors are very grateful to the Energy Research Center of Netherlands (ECN) for their support with the experimental work.

\section{References}

[1] Harby K, Gebaly D, Koura N, and Hassan M. Performance improvement of vapor compression cooling systems using evaporative condenser: An overview. Renew Sustain Energy Rev 2016;58:347-360.

[2] Hamdy M, Askalny A, Harby K, Kora N. An overview on adsorption cooling systems powered by waste heat from internal combustion engine. Renew Sustain Energy Rev 2015;51;1223-1234.

[3] Vasta S, Freni A, Sapienza A, Costa F, Restuccia G. Development and lab-test of a mobile adsorption air-conditioner. International Journal of Refrigeration 2012;35; 701708.

[4] Verde M, Cortés L, Corberán JM, Sapienza A, Vasta S, Restuccia G. Modelling of an adsorption system driven by engine waste heat for truck cabin A/C. Performance estimation for a standard driving cycle. Appl Therm Eng 2010;30:1511-22.

[5] Tamainot-Telto Z, Metcalf SJ, Critoph RE. Novel compact sorption generators for car air conditioning. International Journal of Refrigeration 2009;32:727-733.

[6] Wang DC, Xia ZZ, and Wu JW. Design and performance of a novel zeolite-water adsorption air conditioner. Energy Conversion and Management 2006;47:590-610.

[7] Jiangzhou S, Wang RZ, Lu YZ, Xu YX, Wu JY. Experimental investigations on adsorption air-conditioner used in internal-combustion locomotive driver-cabin. Appl. Therm. Eng 2002;22:1153-1162. 
[8] Zhang LZ. Design and testing of an automobile waste heat adsorption cooling system. Applied Thermal Engineering 2000;20:103-114.

[9] Suzuki M. Application of adsorption cooling systems to automobiles. Heat Recovery Systems \& CHP 1993;13:335-340.

[10] Maggio G, Freni A, and Restuccia G. A dynamic model of heat and mass transfer in a double-bed adsorption machine with internal heat recovery. International Journal of Refrigeration 2006;29:589 -600.

[11] Zhang LZ, and Wang L. Performance estimation of an adsorption cooling system for automobile waste heat recovery. Applied Thermal Engineering 1997;17:1127-1139.

[12] Chua HT, Ng KC, Wang W, Yap C, and Wang XL. Transient modeling of a two-bed silica gel-water adsorption chiller. International Journal of Heat and Mass Transfer 2004;47:659-669.

[13] Miyazaki T, and Akisawa A. The influence of heat exchanger parameters on the optimum cycle time of adsorption chillers. Applied Thermal Engineering 2009;29:2708-2717.

[14] Alam KC, Saha BB, Kang YT, Akisawa A, and Kashiwagi T. Heat design effect on the performance of silica gel adsorption refrigeration systems. International Journal of Heat and Mass Transfer 2000;43:4419-4431.

[15] Alam KC, Kang YT, Saha BB, Akisawa A, and Kashiwagi T. A novel approach to determine optimum switching frequency of a conventional adsorption chiller. Energy 2003;28:1021-1037.

[16] Hamid NH, Mahdavikhah M. Bed geometrical specifications effects on the performance of silica/water adsorption chillers. International Journal of Refrigeration 2012;35:2261-2274.

[17] Verde M, Harby K, B Robert, Corberán JM. Modeling and performance evaluation of a waste-heat driven adsorption chiller for automotive air-conditioning: Part I - Model description and experimental validation, Energy, submitted for publication.

[18] European project TOPMACS-Thermally Operated Mobile Air-Conditioning Systems, funded by the European Comission under the $6^{\text {th }}$ European Community framework program (Contract Ref. TST4-CT-2005-012471). 